\title{
Morphine promotes renal pathology in sickle mice
}

This article was published in the following Dove Press journal: International Journal of Nephrology and Renovascular Disease 19 July 2012

Number of times this article has been viewed

\section{Marc L Weber' \\ Derek Vang² \\ Paulo E Velho ${ }^{2,3}$ \\ Pankaj Gupta ${ }^{4}$ \\ John T Crosson ${ }^{5}$ \\ Robert P Hebbel ${ }^{2}$ \\ Kalpna Gupta ${ }^{2}$}

'Division of Renal Diseases and Hypertension; ${ }^{2}$ Vascular Biology Center and Division of Hematology, Oncology and Transplantation, Department of Medicine, University of Minnesota Medical School, Minneapolis, MN, USA; ${ }^{3}$ Department of Medicine, University of Campinas Medical School, Campinas, SP, Brazil; ${ }^{4}$ Division of Hematology, Oncology and Transplantation, Department of Medicine, University of Minnesota and VA Medical Center, Minneapolis, MN, USA; ${ }^{5}$ Department of Lab Medicine Pathology, Hennepin County Medical Center, Minneapolis, MN, USA
Correspondence: Kalpna Gupta Vascular Biology Center, Medicine Hematology, Oncology and Transplantation, University of Minnesota, Mayo Mail Code 480, 420 Delaware St SE, Minneapolis, MN 55455, USA

$\mathrm{Tel}+\mathrm{I} 6126257648$

Fax +I 6126256919

Email gupta014@umn.edu
Abstract: Patients with sickle cell disease (SCD) are often treated with opioids for severe pain. Although opioids are known to have renal-specific effects, their role in nephropathy in SCD remains unknown. Because a subset of patients receives opioids for long periods of time, we examined the influence of chronic morphine treatment on mice with pre-existing renal disease expressing varying amounts of sickle hemoglobin. Morphine treatment for 3-6 weeks resulted in a variety of defects in renal morphology observed using light and electron microscopy. Notably, morphine induced glomerular pathology, resulting in increased glomerular volume, mesangial expansion, mesangial cell proliferation, parietal cell metaplasia, podocyte effacement, and microvillus transformation. Cystic tubulopathy and hemeoxygenase-1 expression and activity were also increased in morphine-treated mice. Naloxone, a non-selective opioid receptor (OR) antagonist, ameliorated these effects. Functionally, the urine albumin to creatinine ratio was increased following acute as well as chronic morphine treatment. These results suggest that clinically relevant doses of morphine induce renal pathology and that OR antagonists may be effective for ameliorating morphine-induced renal disease.

Keywords: mesangial cell, morphine, nephropathy, pain, podocyte, sickle cell disease

\section{Introduction}

Sickle nephropathy is recognized as a devastating manifestation of sickle cell disease (SCD). ${ }^{1}$ Although the pathophysiology of sickle nephropathy is not completely understood, potential etiologic factors include the mechanical effects of red blood cell (RBC) sickling, hyperfiltration, oxidant-mediated damage, and unintended side effects related to medical therapies. ${ }^{2-4}$ Sickle patients commonly use opioids long-term due to "crises" and chronic pain treatment; ${ }^{5}$ these patients often require higher doses than those with other diseases due to alterations in drug pharmacokinetics and metabolism as well as increased renal clearance. ${ }^{6}$ Via opioid receptors (ORs), opioids induce kidney disease in rodents. ${ }^{7-9}$ Thus, opioids may exacerbate renal disease during SCD. However, the effect of opioid use on kidney disease remains unknown.

Opioids act via three well-defined G-protein coupled receptors (GPCRs): mu-, delta-, and kappa-opioid receptors (MOR, DOR, and KOR, respectively), as well as other undefined receptors. In addition to analgesia induction, opioids activate growth, survival, and cytoprotection via ORs in multiple cell types in peripheral organs and in the central nervous system (CNS). ${ }^{10-12}$ An association between morphine and renal disease was first identified more than three decades ago when heroin-associated nephropathy was recognized in chronic drug abusers, implicating morphine (a metabolite 
of heroin) as a possible etiologic agent. ${ }^{13}$ Our previous study showed that chronic administration of morphine, a MOR agonist, in clinically relevant doses results in significant glomerular pathology, including mesangial growth, glomerular enlargement, and increased proteinuria in tumor-bearing and wild-type (WT) mouse kidneys. ${ }^{8,9}$ Earlier studies from other laboratories revealed that morphine directly stimulates mesangial cell, medullary interstitial cell, and fibroblast proliferation in vitro. ${ }^{14-16}$ These data indicate that morphine inadvertently promotes renal disease in SCD. We therefore examined whether morphine adversely affects renal morphology and function in the kidneys of transgenic sickle mice with the long-term goal of developing strategies for preventing, treating, or delaying nephropathy onset in SCD patients.

\section{Materials and methods Mice}

All mouse studies were performed with prior approval from the Institutional Animal Care and Use Committee (\#0806A37663).

We used three transgenic murine models expressing human sickle hemoglobin to determine whether the effect of morphine on the kidney is strain-specific and/or influenced by the variability of sickle hemoglobin expression. NY1DD mice exhibit a very mild (and non-hemolytic and non-anemic) phenotype, are homozygous for deletion of murine $\beta$-globin, and carry a single copy of linked trans-

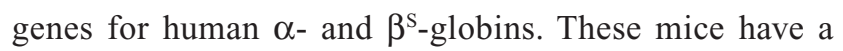
C57BL/6 genetic background. ${ }^{17}$ WT C57BL/6 mice were used as controls for NY1DD. BERK mice are homozygous for knockout of both murine $\alpha$ and $\beta$ globins and carry a single copy of linked transgenes for human $\alpha$ and $\beta^{\mathrm{s}}$ globins. Therefore, BERK mice express human $\alpha$ and $\beta^{\mathrm{s}}$ globin chains (ie, human hemoglobin $\mathrm{S}$ ), but no murine $\alpha$ or $\beta$ globins. ${ }^{18}$ These mice have severe disease resembling human sickle cell anemia, exhibiting hemolysis, reticulocytosis, anemia, extensive organ damage, and a shortened life span. hBERK1 mice are homozygous for knockout of murine $\alpha$ globin, hemizygous for knockout of murine $\beta$ globin, and carry a single copy of linked transgenes for human $\alpha$ and $\beta^{\mathrm{s}}$ globins. ${ }^{18}$ hBERK1 mice express the globin chains human $\alpha$, human $\beta^{\text {s }}$, and murine $\beta$ (human hemoglobin $\mathrm{S}$ and hybrid human $\alpha /$ mouse $\beta$ hemoglobin) and show renal pathology. ${ }^{19}$ Both BERK and hBERK1 have the same mixed genetic background and can be bred as littermates. Control hemoglobin A (HbA)-BERK mice have the same mixed background as BERK and hBERK1, but exclusively express human $\alpha$ and $\beta^{\mathrm{A}}$ globins (thus, normal human hemoglobin A), but no murine $\alpha$ or $\beta$ globins. ${ }^{18}$ Mice were bred in a pathogen-free facility, maintained under controlled environmental conditions (12-hour light-dark cycle, $23^{\circ} \mathrm{C}$ ), and were genotyped and phenotyped using isoelectric focusing and, when necessary, real-time polymerase chain reaction to identify the transgene number.

\section{Drugs and treatments}

Sickle hemoglobin-expressing mice with pre-existing renal pathology and their controls were treated with vehicle (phosphate-buffered saline [PBS]) or morphine for 3 and 6 weeks, with or without coadministration of the OR antagonist naloxone. Injectable morphine sulfate and naloxone were obtained from Baxter Esilerderle Healthcare (Cherry Hill, NJ) and Hospira Inc (Lake Forest, IL), respectively. Each day, mice were injected subcutaneously with increasing doses of pharmacological grade morphine $(0.75,1.4,2.14$, $2.8,3.6$, and $4.3 \mathrm{mg} / \mathrm{kg} /$ day in two divided doses during the $1 \mathrm{st}, 2 \mathrm{nd}, 3 \mathrm{rd}$, 4th, 5th, and 6 th weeks, respectively, which is equivalent to approximately 50-301 mg/70 kg human/day). Naloxone was used in a dose equivalent to $10 \mathrm{mg} / 70 \mathrm{~kg} /$ day. Sex- and age-matched mice were treated with PBS. Mice were treated for a total of 3 or 6 weeks, and euthanized at the end of treatment using $\mathrm{CO}_{2}$. Kidneys were excised, weighed, and processed for analysis.

\section{Histology}

Formalin-fixed, paraffin-embedded kidney sections were cut at $4 \mu \mathrm{m}$ and stained with (i) Periodic acid-Schiff (PAS) stain and counterstained with hematoxylin, and (ii) hematoxylin and eosin (H\&E) and analyzed by a renal pathologist in a double-blind manner. Images were visualized using a Zeiss AXIOPHOT microscope (Carl Zeiss Microscopy, LLC, Thornwood, NY) with a $10 \times$ eyepiece and a $40 \times$ or $100 \times$ objective. Photographs were acquired using an Olympus DP70 camera and 160ME digital camera interface using Olympus DP Manager version 3-11288 (Olympus Corporation, Tokyo, Japan).

\section{Electron microscopy}

Kidney sections were collected in $4 \%$ formaldehyde and $1 \%$ glutaraldehyde, washed in PBS, placed in osmium for 90 minutes, washed in acetone, embedded in epon, and dried overnight. One-micron-thin sections stained with methylene azure II blue were evaluated using light microscopy to select blocks for electron microscopy. Selected blocks were cut in 500-nM thick sections using a diamond knife, placed on a wire grid, stained with uranyl acetate and lead citrate, 
and evaluated on a JEM 1011 electron microscope (JEOL, Tokyo, Japan). Electron micrographs were acquired using the built-in camera.

\section{Glomerular volume measurement}

Morphometric analysis was performed on $4-\mu \mathrm{m}$ PAS-stained kidney sections and based on the method of point counting as described previously. ${ }^{9}$ Thirty glomeruli were counted for each kidney. The area of the entire glomerulus, including the glomerular tuft, the urinary space, and the Bowman's capsule was included for volume estimation.

\section{Urine albumin and creatinine}

Urine albumin and creatinine were analyzed using the AssayMax Mouse Albumin ELISA Kit (catalog no EMA3201-1, AssayPro, St Charles, MO) and the Creatinine assay kit (Cayman Chemicals, Ann Arbor, MI), respectively, according to the manufacturers' instructions.

\section{Northern analysis of heme oxygenase I (HO-I) mRNA expression}

HO-1 mRNA expression in the kidney was assessed using Northern analysis as described previously. ${ }^{20}$ Briefly, RNA was extracted from the kidneys using the Trizol method, separated on an agarose gel, and transferred to a nylon membrane. The membrane was hybridized overnight with a ${ }^{32} \mathrm{P}$-labeled human HO-1 cDNA probe. Densitometry of the autoradiogram was performed and standardized by factoring optical density of HO-1 with the optical density of the 18S rRNA. Optical density of the 18S rRNA was obtained from a negative of the ethidium bromide-stained nylon membrane.

\section{Measurement of renal $\mathrm{HO}$ activity}

$\mathrm{HO}$ activity was assessed by measuring the rate of bilirubin generation by microsomes prepared from kidneys as described previously. ${ }^{21}$ Briefly, microsomes were incubated with mouse liver cytosol (a source of biliverdin reductase), hemin $(20 \mu \mathrm{M})$, glucose-6-phosphate ( $2 \mathrm{mM})$, glucose-6phosphate dehydrogenase $(4 \mathrm{U} / \mathrm{mL})$, and NADPH $(0.8 \mathrm{mM})$ for 90 minutes at $37^{\circ} \mathrm{C}$ in the dark. Bilirubin was extracted using chloroform; the difference in optical density (OD) at $464-530 \mathrm{~nm}$ (extinction coefficient, $40 \mathrm{mM} / \mathrm{cm}$ for bilirubin) was measured, and enzyme activity was determined (pmolbilirubin formed $/ \mathrm{h} / \mathrm{mg}$ protein).

\section{Data and statistical analysis}

Data are expressed as the mean \pm standard deviation (SD) or standard error of the mean (SEM). One-way analysis of variance
(ANOVA) with Tukey's post-test or Student's $t$-test, as applicable, was performed using GraphPad Prism version 5.04 for Windows (GraphPad Software, Inc, La Jolla, CA). Because of unequal sample sizes and multiple groups, Tukey's post-test was selected for analysis. Statistical significance was defined as $P<0.05$.

\section{Results}

\section{Mouse models of kidney disease in SCD}

We used three transgenic mouse models exhibiting kidney abnormalities characteristic of human SCD and expressing varying levels of sickle hemoglobin (HbS). Mouse models used included hBERK1 ( 26\% HbS), NY1DD ( 40\% HbS), and BERK ( $\sim 99 \% \mathrm{HbS}) .{ }^{17-23}$ Age- and sex-matched control WT C57BL/6 mice $(0 \% \mathrm{HbS})$ were on the same genetic background as NY1DD and HbA-BERK mice $(0 \% \mathrm{HbS})$ were on the same mixed genetic background as hBERK1 and BERK (littermates). HbA-BERK mice express normal human $\mathrm{HbA}$. hBERK1 mice were used, although these mice express lower levels of $\mathrm{HbS}$ because they develop kidney disease and pain. ${ }^{19,22-24}$ Morphine-induced renal pathology observed in this study in mice from different genetic backgrounds suggest that these effects are not influenced by the strains of the mice. Table 1 shows different transgenic mice, controls, and number of mice used in this study.

\section{Baseline kidney characteristics of mouse models and controls}

As described previously, transgenic sickle mice exhibited pathological abnormalities in kidney tissue as compared to their strain-specific background controls. ${ }^{17-19} \mathrm{HbA}$-BERK controls exhibited parietal epithelial cell (PEC) metaplasia in many glomeruli, which were larger compared to C57BL/6 controls (not shown) as we previously reported. ${ }^{9}$ Our previous study showed that the kidneys of untreated C57BL/6 mice showed no pathological abnormalities except for slight hypertrophy of PECs in males and vascular congestion. ${ }^{9}$ Although tubules in HbA-BERK kidneys were

Table I Number of mice for different treatments used in the study

\begin{tabular}{llllll}
\hline $\begin{array}{l}\text { Type } \\
\text { of mouse }\end{array}$ & PBS & Morphine & $\begin{array}{l}\text { Naloxone + } \\
\text { morphine }\end{array}$ & Naloxone & Figure \# \\
\hline NYIDD & 6 & 6 & 6 & 6 & I and 6 \\
hBERKI & 6 & 6 & 6 & 6 & 2 and 6 \\
HbA-BERK & 6 & 6 & None & None & 2 \\
BERK & 6 & 6 & None & None & 3 , 5, and 6 \\
BERK & 4 & 4 & None & None & 4 \\
NYIDD & 6 & 6 & 6 & 6 & 5 \\
hBERKI & 6 & 6 & 3 & 3 & 5 \\
\hline
\end{tabular}

Abbreviations: HbA, hemoglobin A; PBS, phosphate-buffered saline. 
more dilated compared to C57BL/6 kidneys, no vascular congestion was observed (not shown), revealing strainspecific variability.

\section{Morphine treatment alters the histology and ultrastructure of kidneys in sickle mice}

All mice were treated with increasing doses of morphine similar to those used in patients with SCD. Mice were treated with vehicle (PBS) or morphine for 3 (NY1DD) and 6 (hBERK1 and BERK) weeks. NY1DD and hBERK1 mice were also treated with or without coadministration of an OR antagonist, naloxone, for 3 and 6 weeks, respectively. The minimum 3-week treatment period was chosen based on our previous study showing that morphine-induced mesangial glomerular volume was optimum 3 weeks after morphine treatment in $\mathrm{C} 57 \mathrm{BL} / 6$ mice. $^{9}$

\section{Light microscopy of transgenic NYIDD sickle mice kidneys}

Three weeks of morphine treatment induced glomerular expansion, tubular dilatation, and intraglomerular and peritubular congestion compared to mice treated with PBS (Figure 1). In the cortico-medullary region, sloughing of epithelial cells and loss of brush border was observed in some morphine-treated but not in PBS-treated mice (Figure 1D, green arrow). A higher magnification image from a morphine-treated mouse kidney shows increased juxtaglomerular cells and extremely high intraglomerular congestion (Figure 1E).

\section{Light microscopy of transgenic hBERK I} and HBA-BERK mice kidneys

Morphine treatment of hBERK1 for 6 weeks led to alterations similar to those observed in morphine-treated NY1DD mice, except for tubular dilatation, which did not increase upon morphine treatment in hBERK1 mice. As described above, tubules of hBERK1 mice were more dilated than those of NY1DD mice at baseline, perhaps due to strain differences. Increased cellularity of mesangial and juxtaglomerular cells and PEC metaplasia resembling tubular epithelial cells were observed in hBERK1 mice treated with morphine as compared to mice treated with PBS (Figure 2A-D). Co-treatment with naloxone antagonized morphine-induced pathological changes, suggesting an OR-mediated mechanism (Figure 2C). Naloxone alone did not influence renal pathology in hBERK1 mice (Figure 2D). Control HbA-BERK mice expressing normal human hemoglobin also showed increased
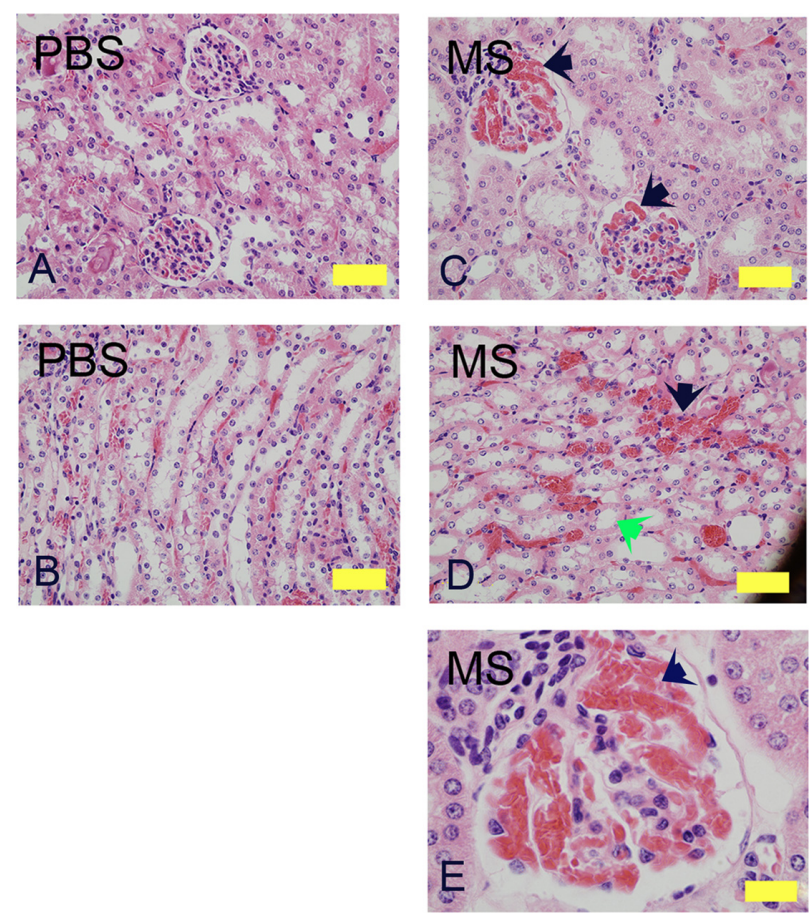

Figure I Morphine treatment exacerbates renal pathology in NYIDD mice. H\&E stained kidney sections of NYIDD mice treated with morphine for 3 weeks. Cortical and cortico-medullary regions with glomerular and tubular histology are shown. Glomerular and tubular morphology in PBS-treated mouse kidneys (A and B). Note the severe intraglomerular congestion ( $\mathbf{C}$ and $\mathbf{E}$, black arrows), tubular dilatation and loss of brush border (D, green arrow), and peritubular congestion (black arrow) in morphine-treated mice.

Notes: Magnification (A-D): $\times 400$; scale bar, $125 \mu \mathrm{M}$. E, $\times 1000$; scale bar, $50 \mu \mathrm{M}$. Each photomicrograph is representative of kidney tissue from 6 mice each.

Abbreviations: H\&E, hematoxylin and eosin; MS, morphine sulfate, PBS, phosphatebuffered saline.

glomerular enlargement after 6 weeks of morphine treatment as compared to treatment with PBS (Figure 2E and F). These data suggest that morphine-induced pathology is independent of the strain of transgenic mice expressing sickle hemoglobin. Furthermore, mice did not develop a tolerance to the effect of morphine in the kidneys even after prolonged treatment for up to 6 weeks.

\section{Light microscopy of transgenic BERK mice kidneys}

Similar to NY1DD and hBERK1 mice, morphine treatment for 6 weeks resulted in glomerular and tubular changes in BERK mice (Figure 3). Morphine-treated mice show increased glomerular volume and extremely high PEC metaplasia as compared to PBS-treated BERK mice (Figure 3A, C and $\mathrm{E}$, green arrows). Peritubular congestion was remarkably high in morphine-treated mice as compared to PBS-treated BERK mice (Figure 3B and D, black arrows). Morphineinduced tubular pathology showed epithelial cells sloughing off from the basement membrane, loss of brush border, and proteinaceous deposits (Figure 3C and D, yellow and turquoise arrows), suggesting tubular injury. 

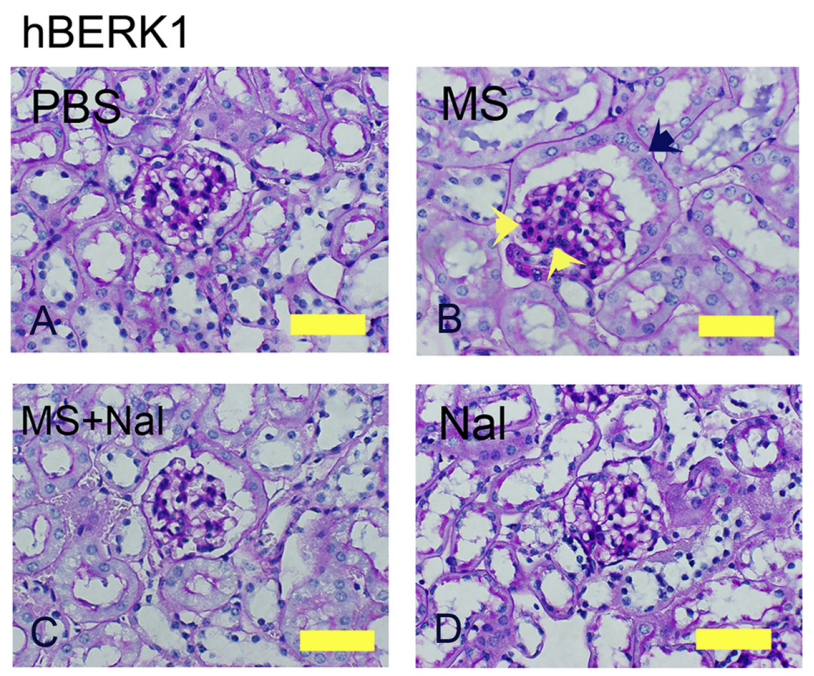

HbA-BERK
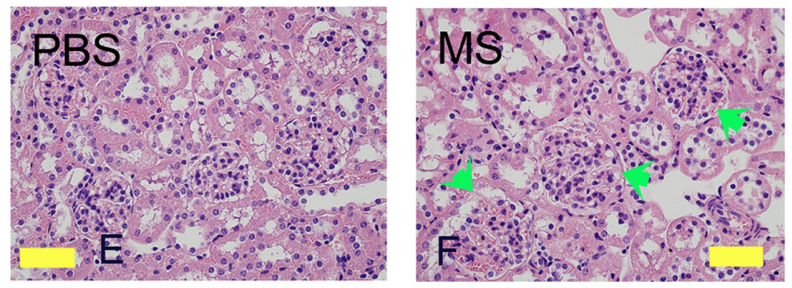

Figure 2 Morphine treatment exacerbates renal pathology in hBERKI and $\mathrm{HbA}$ BERK mice. (A-D) PAS-stained kidney sections from hBERKI mice treated with morphine and/or naloxone for 6 weeks. Note the glomerular enlargement, increased mesangial cell density (black arrow), and parietal cell metaplasia (green arrow) in (B).

Notes: Magnification $\times 780$; scale bar, $50 \mu \mathrm{M}$. (E and F) H\&E-stained kidney sections from HbA-BERK mice treated with morphine for 6 weeks. Note the glomerular enlargement in $\mathrm{F}$ (green arrows). Magnification $\times 400$; scale bar, $125 \mu \mathrm{M}$. Each photomicrograph is representative of kidney tissue from 6 mice each.

Abbreviations: H\&E, hematoxylin and eosin; HbA, hemoglobin A; MS, morphine sulfate; Nal, naloxone; PAS, periodic acid-Schiff; PBS, phosphate-buffered saline.

\section{Electron microscopy of BERK mice kidneys}

Electron microscopy revealed mild to moderate mesangial prominence, with a mild increase in mesangial cells, slightly increased foot process effacement, prominence of red cell fragments, and electron dense iron deposits in the kidneys of BERK mice treated with morphine for 3 weeks as compared to PBS-treated BERK mice (Figure 4). Foot processes, the mesangial region containing mesangial cells, and the mesangial matrix appeared to be normal in PBS-treated BERK mice (Figure 4A and B). Foot process effacement and marked microvillus transformation were accompanied by increased mesangial cell proliferation and mesangial matrix, resulting in an expanded mesangial area without evidence of immune complexes in the kidneys of morphine-treated mice (Figure 4C-E).

Morphine treatment significantly increased glomerular volume in mouse kidneys. Morphine treatment for 3-6 weeks

\section{A BERK}
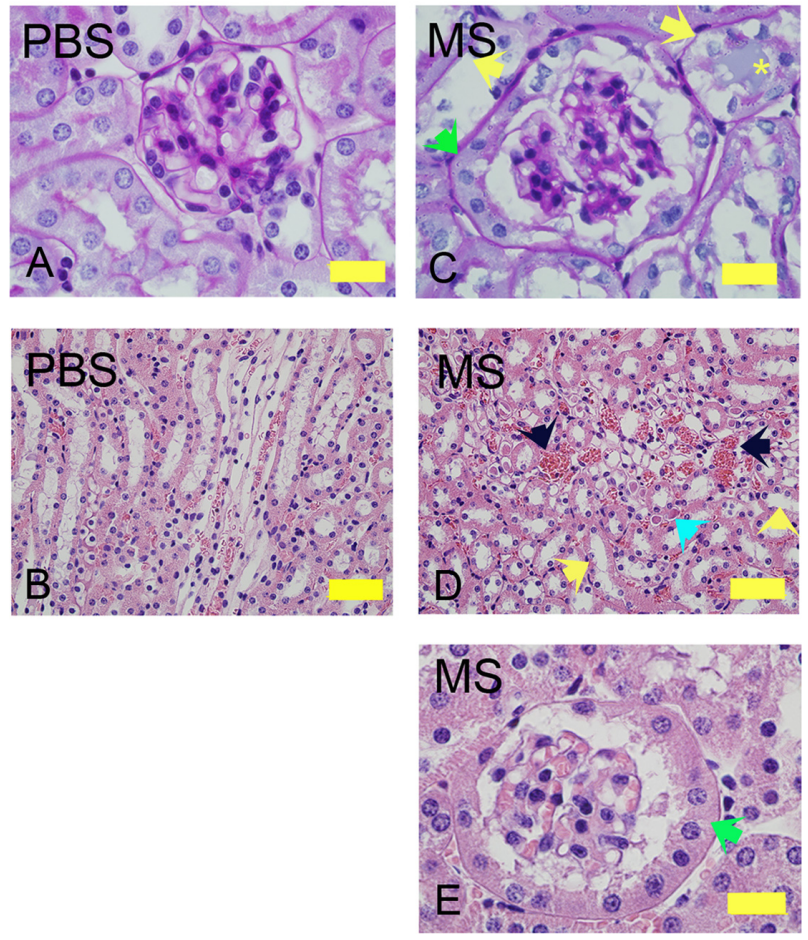

Figure 3 Morphine treatment exacerbates renal pathology in BERK mice. Kidney sections from BERK mice treated with PBS or MS for 6 weeks. (A and C) Glomeruli stained with PAS to show the basement membrane. Note that the tubules in PBStreated mice are lined with intact epithelium and a brush border. In morphinetreated mice (C), the glomerulus is much larger than that in PBS-treated and shows parietal cell metaplasia (green arrow); tubules show basement membrane without epithelial cells (left yellow arrow) or epithelial cells sloughing off of the basement membrane (right yellow arrow) with a proteinaceous deposit (yellow*). Parietal epithelial cell metaplasia can be seen more prominently at the higher magnification in (E) (green arrow). In (D), the H\&E-stained images show prominent vascular congestion (black arrows), early tubular epithelial cell necrosis (left yellow arrow), loss of epithelial cells and brush border (right yellow arrow), and proteinaceous deposits (turquoise arrow).

Notes: Magnification $\times 1000$ (A, C, and E) and $\times 400$ (B and D); scale bar, $50 \mu$ M. Abbreviations: H\&E, hematoxylin and eosin; MS, morphine sulfate; PAS, periodic acid-Schiff; PBS, phosphate-buffered saline.

led to significantly increased glomerular volume in the kidneys of HbS-expressing and HbA-BERK mice as compared to PBS-treated mice (Figure 5). Glomerular volume increased by $22 \%$ in NY1DD mice $(P<0.01)$ after 3 weeks of morphine treatment and by $26 \%$ and $22.5 \%$ in hBERK1 mice $(P<0.01)$ and BERK mice $(P<0.05)$, respectively, after 6 weeks of morphine treatment as compared to PBS treatment. Naloxone antagonized morphine-induced glomerular enlargement, suggesting an OR-mediated effect (Figure 5).

\section{Morphine increases kidney weight in sickle mice}

Mice did not show a significant gain or loss in body weight after morphine and/or naloxone treatment as compared to PBS-treated mice (data not shown). Fractional kidney mass 

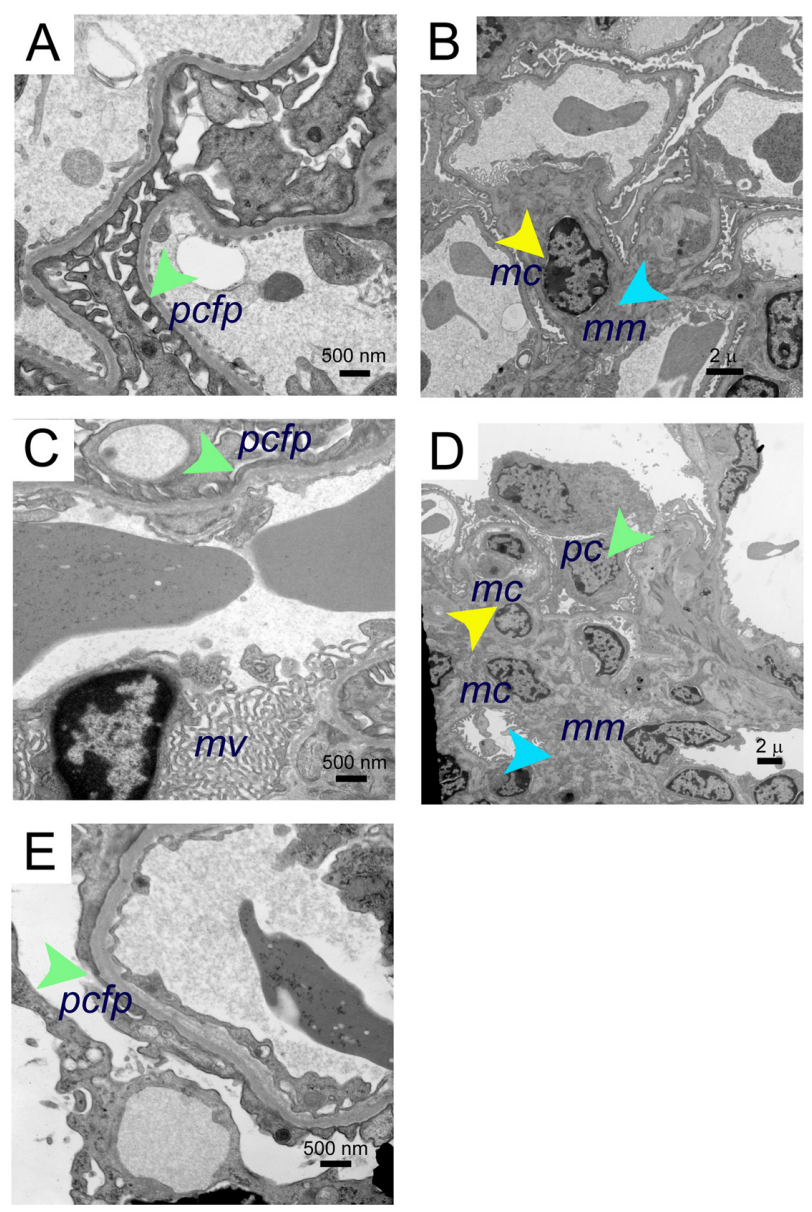

Figure 4 Electron microscopy images of morphine-induced glomerular alterations in BERK-sickle mice. Electron micrographs of kidneys from BERK mice treated with PBS or morphine for 3 weeks. (A and B) Electron micrographs of kidneys from PBS-treated BERK mice. (A) Normal podocyte foot processes (green arrow) and (B), normal mesangial region (mesangial cell, yellow arrow and mesangial matrix, turquoise arrow) in male BERK mice treated with PBS. (C-E) Electron micrographs of BERK mice treated with morphine for 3 weeks. (C) Foot process effacement (green arrow) and marked microvillus (mv) transformation in the kidney of female BERK mice treated with morphine. (D) Marked expansion of mesangial matrix (turquoise arrow), podocyte (green arrow), and increased mesangial cells (yellow arrow), but no immune complexes in the kidneys of male BERK mice treated with morphine. (E) Foot process effacement (green arrow) in the kidney of male BERK mice.

Notes: Scale bar, $500 \mathrm{~nm}$ (A, C and E), and $2 \mu \mathrm{m}$ (B and D). Electron micrographs represent 4 each BERK mice ( 2 males and 2 females) treated with PBS or morphine. Abbreviations: $\mathrm{mc}$, mesangial cell; $\mathrm{mm}$, mesangial matrix; mv, microvillus; pcfp, podocyte foot processes; PBS, phosphate-buffered saline.

increased by $23 \%$ in NY1DD mice after 3 weeks of morphine treatment and by $40 \%$ in hBERK1 mice after 6 weeks of treatment compared to PBS-treated mice (Figure 6A). Co-treatment with naloxone antagonized this morphine-induced increase in kidney mass, suggesting that morphine acts through an OR-mediated mechanism. Naloxone treatment alone had no significant effect on kidney weight. Morphine treatment also increased kidney weight in BERK mice by $31 \%$ after 6 weeks compared to that in PBS-treated mice. No changes in body weight or behavior were associated with morphine treatment as compared to body weight and behavior in PBS-treated mice.

\section{Morphine induces albuminuria}

Treatment of NY1DD mice with morphine significantly increased urine albumin to creatinine ratios $24 \mathrm{~h}$ after treatment; these values remained increased over a period of 3 weeks (Figure 6B). These data suggest that renal histopathological alterations induced by morphine are associated with functional abnormalities in mice expressing $\mathrm{HbS}$.

\section{Morphine increases heme oxygenase $(\mathrm{HO})$ in the kidney}

HO-1 is upregulated in the kidneys of mice and humans with $\mathrm{SCD},{ }^{25}$ and chronic morphine increases $\mathrm{HO}$ in the spinal cord and kidney. ${ }^{8,26}$ Morphine treatment likely further increases $\mathrm{HO}$ as a stress response. We therefore examined the effect of chronic morphine treatment on $\mathrm{HO}$ activity and HO-1 mRNA expression in hBERK1 mouse kidneys. Treatment with morphine for 3 weeks resulted in a significant increase in $\mathrm{HO}$ activity and HO-1 mRNA in hBERK1 kidneys $(P<0.001$ and 0.01 , for activity and mRNA, respectively, versus PBS [Figure 7]). Similar effects were observed in control HbABERK kidneys, suggesting that chronic morphine treatment leads to increased $\mathrm{HO}$ activity in the kidneys, irrespective of sickle $\mathrm{Hb}$ expression in mice.

\section{Discussion}

Nephropathy is a major factor contributing to morbidity in $\mathrm{SCD}$. The present study demonstrates that chronic exposure to morphine promotes renal injury in sickle mice. Additionally, our data show that chronic opioid exposure inadvertently leads to development of renal disease in non-sickle mice in the absence of underlying pathology. We also demonstrate that morphine impairs renal function, in part through histopathologic alterations in the glomerulus. Using two different strains of mice (NY1DD on C57BL/6) and BERK/hBERK1 (on mixed background), we reveal distinguishable features of morphine-induced strain-specificity in the kidney.

Opioids and their receptors were once thought to have an exclusive role in the CNS, but have also been identified to have activity in the kidney. ${ }^{9,27,28}$ While it is unclear whether increased MOR and KOR expression is a cause or consequence of renal disease, OR antagonism by naloxone suggests that morphine-induced renal effects are mediated by ORs.

Glomerular enlargement is thought to result in increased urinary protein excretion and to be a precursor of glomerular sclerosis. ${ }^{29}$ We observed increases in kidney weight, glomerular volume, and urinary albumin excretion in sickle mice exposed to morphine treatment. Additionally, glomerular epithelium is critically important in the development of 

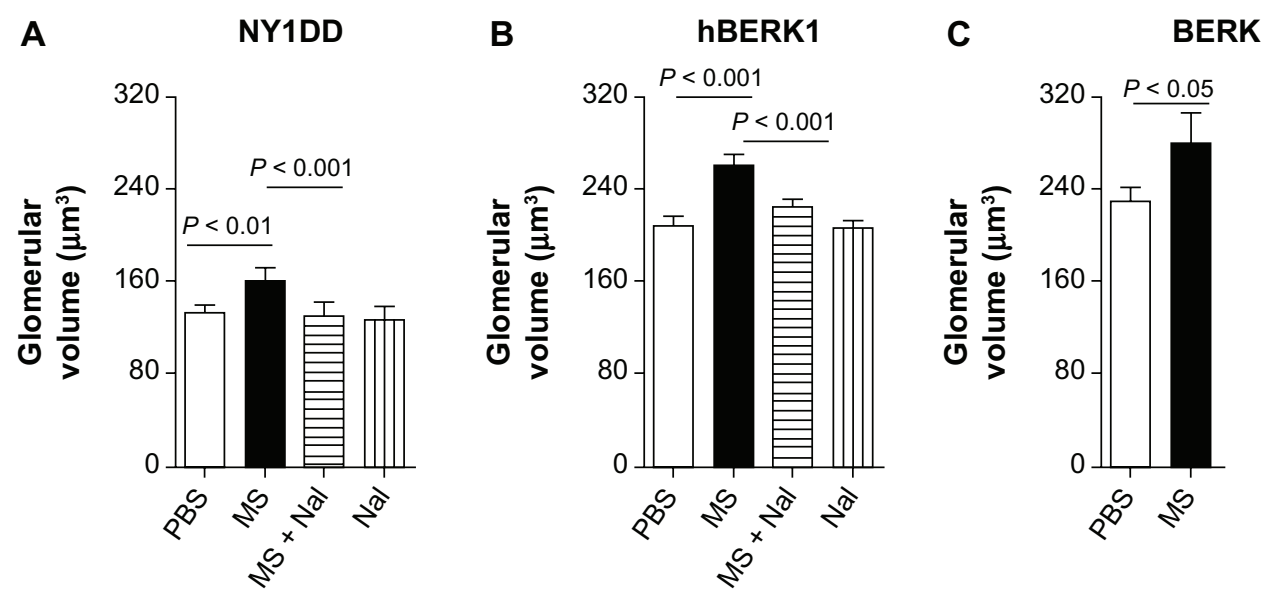

Figure 5 Morphine treatment increases glomerular volume. (A-C) Glomerular volume of NYIDD (A), hBERKI (B), and BERK (C) mice treated with morphine and/ or naloxone for 3 or 6 weeks as indicated. Note that morphine stimulates a significant increase in glomerular volume, which is abrogated by co-treatment with naloxone, although naloxone alone did not alter glomerular volume.

Notes: Each bar represents the mean \pm SD of 3-6 mice/group; equal numbers of male and female mice were used except in one group (I male and 2 females).

Abbreviations: MS, morphine sulfate; Nal, naloxone; PBS, phosphate-buffered saline; SD, standard deviation.

A NY1DD 3 wk treatment

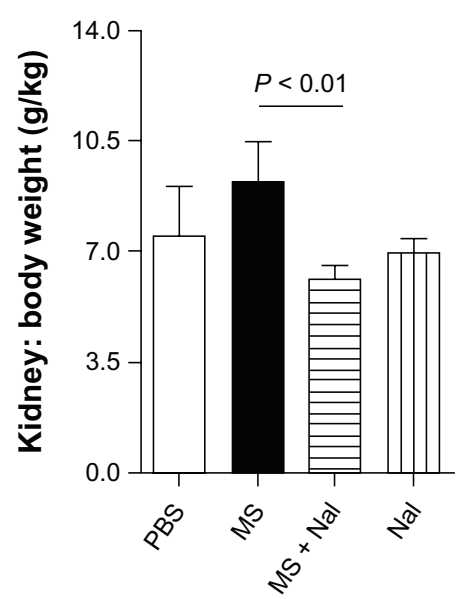

B

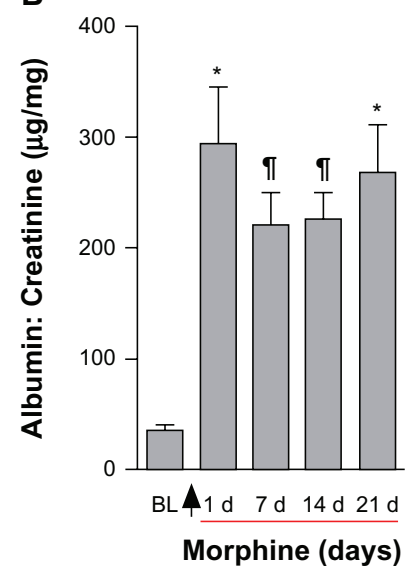

hBERK1 6 wk treatment

BERK 6 wk treatment
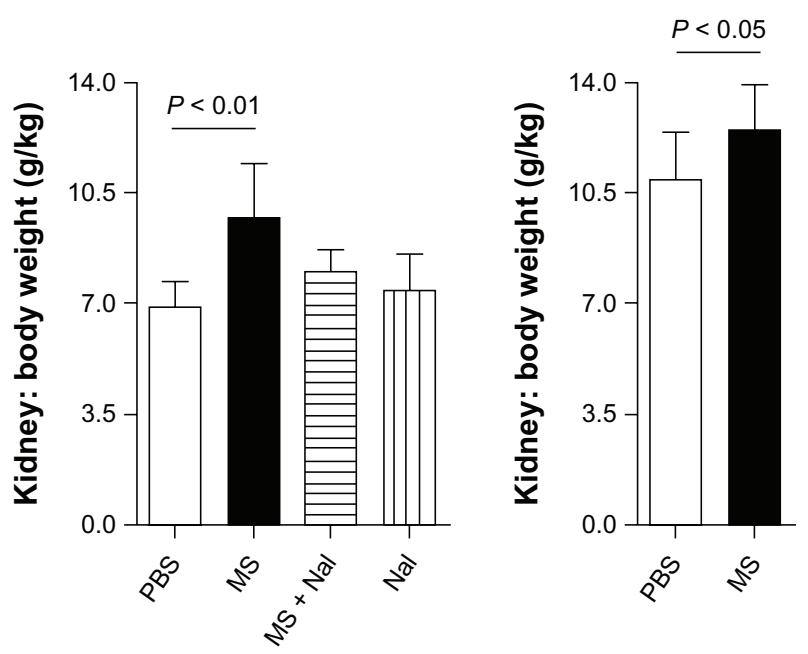

Figure 6 Morphine treatment increases kidney weight and urine albumin. (A) Kidney: body weight ratio of NYIDD, hBERKI, and BERK mice treated with morphine as indicated. (B) NYIDD mice were treated with morphine for 3 weeks. Urine was collected before beginning treatment and periodically following treatment.

Notes: Arrow indicates the start of morphine treatment. Morphine treatment showed a highly significant increase in urinary albumin excretion after one day of treatment, which was sustained throughout the 3 -week treatment period as compared to baseline values before beginning treatment. BL refers to baseline measurements obtained before starting morphine treatment. $* P<0.001$ or $\mathbb{T} P<0.01$, compared with $B L$. $N=6$ mice ( 3 females and 3 males).

Abbreviations: MS, morphine sulfate; $\mathrm{Nal}$, naloxone. 


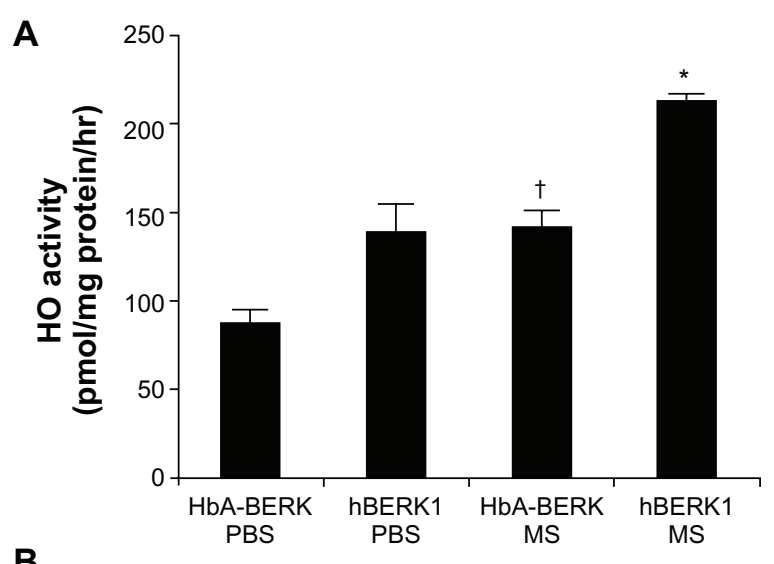

B

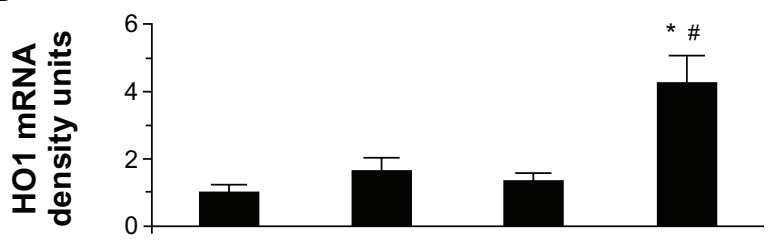

$18 \mathrm{~S}$
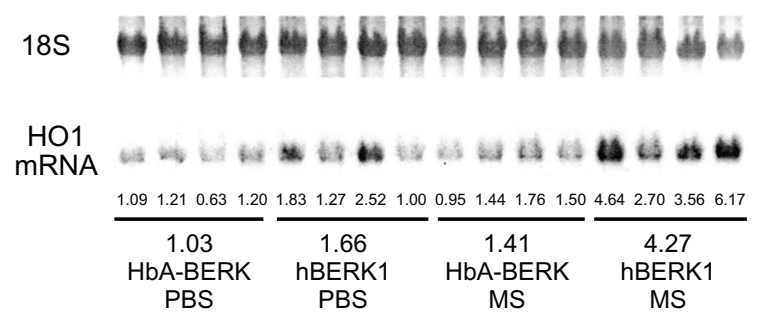

Figure 7 Morphine stimulates heme oxygenase $(\mathrm{HO})$ activity and alters kidney function. (A) HO activity in the kidney of HbA-BERK and hBERKI mice after 3 weeks of morphine treatment. Each bar represents the mean \pm SEM of 4 mice/ group. ${ }^{*} P<0.001$ compared with hBERKI mice treated with PBS or HbA-BERK mice treated with MS; ${ }^{\dagger} P<0.01$ compared with HbA-BERK PBS. (B) HOI mRNA expression in the kidney of $\mathrm{HbA}-\mathrm{BERK}$ and hBERKI mice after 3 weeks of morphine treatment.

Notes: Each bar represents densitometric units of bands obtained from Northern analysis of RNA from the entire kidney. Values are shown as the mean \pm SEM of 4 mice/group. $* P<0.01$ compared with hBERKI mice treated with PBS; ${ }^{*} P<0.00$ I compared with $\mathrm{HbA}-\mathrm{BERK}$ mice treated with MS.

Abbreviations: $\mathrm{HbA}$, hemoglobin A; PBS, phosphate-buffered solution; MS, morphine sulfate; $\mathrm{HOI}$, heme oxygenase $\mathrm{I}$.

kidney disease. Metaplasia of glomerular PEC is a common sign of glomerular injury. It has been suggested that cellular lesions seen in Bowman's space in focal sclerosis (the prominent glomerular lesion seen in sickle cell nephropathy) are derived from proliferating PEC. ${ }^{30}$ The observed increase in PEC metaplasia with prolonged morphine exposure and its antagonism with naloxone further highlight the potential importance of ORs in renal disease. However, naloxone alone did not exacerbate kidney pathology, suggesting that although OR expression is increased in the kidneys of sickle mice, it likely does not contribute to renal pathology in the absence of pharmacological doses of opioids. Increased albuminuria following morphine treatment is consistent with glomerular injury. Although renal pathology inevitably develops in sickle mice, our data suggest that morphine exacerbates the underlying pathologic condition by contributing to glomerular pathology.

Podocytes regulate glomerular function by maintaining the filtration barrier between the capillaries and urinary space. ${ }^{31}$ Even localized podocyte injury induces stress on uninjured podocytes, glomerular endothelium, and mesangial cells, initiating a cycle of progressive glomerular disease. ${ }^{32}$ Consistent with increased albuminuria, morphine treatment resulted in podocyte effacement and microvillus formation, suggesting podocyte injury and disruption of glomerular filtration barrier in sickle mice. An increased number of podocyte microprojections was observed using SEM following one week of morphine treatment in rats. ${ }^{33}$

We also show that tubular damage was exacerbated in morphine-treated mice. These observations are consistent with chronic morphine-induced vacuolization of tubular cells and increases in blood urea nitrogen in the kidneys of Wistar rats. ${ }^{7}$ Furthermore, morphine-induced rheological changes in red blood cells led to the intra- and extra-glomerular capillary vascular congestion in the kidneys of mice treated with morphine. This may contribute in part to the observed glomerular enlargement.

Morphine inhibits the activity of glutathione reductase purified from human erythrocytes. ${ }^{34}$ This may lead to increased oxidative stress in tissues. In previous studies, we observed increased HO-1 activity in the kidneys of sickle mice with renal injury. ${ }^{25} \mathrm{HO}-1$ plays a protective role against cellular insults such as oxidative stress and heme protein-induced injury. ${ }^{35}$ Low concentrations of morphine were shown to increase proliferation and $\mathrm{HO}$ activity in glomerular epithelial cells in vitro. ${ }^{36}$ In the present study, increased $\mathrm{HO}$ activity and HO-1 expression in the kidneys of mice treated with morphine may have been due to increased oxidative stress and serves as a protective mechanism against morphine-induced renal injury. This is a novel finding which requires further investigation.

Clinical studies of sickle cell nephropathy show varying degrees of albuminuria, hyperfiltration, and an altered glomerular filtration rate. ${ }^{37}$ Variable use of opioids may be a contributing factor to physiologic and hematologic renal responses in SCD. Analgesic nephropathy is recognized as a problem, although clinical attention has focused almost exclusively on the roles of non-steroidal anti-inflammatory drugs (NSAIDs) in acute renal failure, development of edema, and hypertension..$^{38}$ Because these opioids are frequently used at high doses, are started at an early age, 
and administered repeatedly throughout life, the clinical implications of our data are significant considering the high incidence of nephropathy in SCD. Therefore, clinical studies are required to directly assess the association of opioid use and nephropathy in patients with SCD.

\section{Authors' contributions}

MLW performed experiments and assisted with writing the manuscript; DV performed urine analysis; PEV interpreted data and wrote the manuscript; JTC and PG analyzed and interpreted histopathology and electron microscopy data; RPH conducted genotyping, provided mice, and gave advice regarding editing of the manuscript; $\mathrm{KG}$ conceived, designed, and supervised the study and analyzed and interpreted data as well as edited the manuscript.

\section{Acknowledgments}

We thank Mariya Farooqui, Tasneem Poonawala, Karl A Nath, Anthony Croatt, Stefan Kren, and Janet Parker for technical assistance. This work was funded by NIH grants, RO1 HL68802, HL103773, HL68802-06S1, HL68802-7S1 (to KG) and PO1 HL55552 (to RPH).

\section{Disclosure}

The authors report no conflicts of interest in this work.

\section{References}

1. Scheinman JI. Sickle cell disease and the kidney. Nat Clin Pract Nephrol. 2009;5(2):78-88.

2. Helal I, Fick-Brosnahan GM, Reed-Gitomer B, Schrier RW. Glomerular hyperfiltration: definitions, mechanisms and clinical implications. Nat Rev Nephrol. 2012;8(5):293-300.

3. Becker AM. Sickle cell nephropathy: challenging the conventional wisdom. Pediatr Nephrol. 2011;26(12):2099-2109.

4. Rees DC, Williams TN, Gladwin MT. Sickle-cell disease. Lancet. 2010;376(9757):2018-2031.

5. Ballas SK. Neurobiology and treatment of pain. In: Embury SH, Hebbel RP, Mohandas N, Steinberg MH, editors. Sickle Cell Disease: Basic Principles and Clinical Practice. New York: Raven Press; 1994:745-772.

6. Dampier CD, Setty BN, Logan J, Ioli JG, Dean R. Intravenous morphine pharmacokinetics in pediatric patients with sickle cell disease. J Pediatr. 1995;126(3):461-467.

7. Atici S, Cinel I, Cinel L, Doruk N, Eskandari G, Oral U. Liver and kidney toxicity in chronic use of opioids: an experimental long term treatment model. J Biosci. 2005;30(2):245-252.

8. Arerangaiah R, Chalasani N, Udager AM, et al. Opioids induce renal abnormalities in tumor-bearing mice. Nephron Exp Nephrol. 2007;105(3):e80-e89.

9. Weber ML, Farooqui M, Nguyen J, et al. Morphine induces mesangial cell proliferation and glomerulopathy via kappa-opioid receptors. $\mathrm{Am}$ J Physiol Renal Physiol. 2008;294(6):F1388-F1397.

10. Gupta K, Stephenson EJ. Existence and modus operandi of opioid receptors in endothelium. In: Aird WC, editor. The Endothelium: A Comprehensive Reference. New York: Cambridge University Press; 2007:451-460.
11. Gupta M, Gupta K. Opioids as promoters and regulators of angiogenesis. In: Maragoudakis ME, Papadimitriou E, editors. Angiogenesis: Basic Science and Clinical Applications. Kerala, India: Transworld Research Network; 2007:303-318.

12. Tegeder I, Geisslinger G. Opioids as modulators of cell death and survival - unraveling mechanisms and revealing new indications. Pharmacol Rev. 2004;56(3):351-369.

13. Kilcoyne MM, Gocke DJ, Meltzer JI, et al. Nephrotic syndrome in heroin addicts. Lancet. 1972;1(7740):17-20.

14. Singhal PC, Sharma P, Gibbons N, Franki N, Kapasi A, Wagner JD Effect of morphine on renomedullary interstitial cell proliferation and matrix accumulation. Nephron. 1997;77(2):225-234.

15. Singhal PC, Sharma P, Sanwal V, et al. Morphine modulates proliferation of kidney fibroblasts. Kidney Int. 1998;53(2):350-357.

16. Singhal PC, Gibbons N, Abramovici M. Long term effects of morphine on mesangial cell proliferation and matrix synthesis. Kidney Int. 1992;41(6):1560-1570.

17. Fabry ME, Nagel RL, Pachnis A, Suzuka SM, Costantini F. High expression of human beta S- and alpha-globins in transgenic mice: hemoglobin composition and hematological consequences. Proc Natl Acad Sci U S A. 1992;89(24):12150-12154.

18. Paszty C, Brion CM, Manci E, et al. Transgenic knockout mice with exclusively human sickle hemoglobin and sickle cell disease. Science. 1997;278(5339):876-878.

19. Diwan BA, Gladwin MT, Noguchi CT, Ward JM, Fitzhugh AL, Buzard GS. Renal pathology in hemizygous sickle cell mice. Toxicol Pathol. 2002;30(2):254-262.

20. Nath KA, Vercellotti GM, Grande JP, et al. Heme protein-induced chronic renal inflammation: suppressive effect of induced heme oxygenase-1. Kidney Int. 2001;59(1):106-117.

21. Liang M, Croatt AJ, Nath KA. Mechanisms underlying induction of heme oxygenase- 1 by nitric oxide in renal tubular epithelial cells. Am J Physiol Renal Physiol. 2000;279(4):F728-F735.

22. Manci EA, Hillery CA, Bodian CA, Zhang ZG, Lutty GA, Coller BS. Pathology of Berkeley sickle cell mice: similarities and differences with human sickle cell disease. Blood. 2006;107(4):1651-1658.

23. Noguchi CT, Gladwin M, Diwan B, et al. Pathophysiology of a sickle cell trait mouse model: human alpha(beta)(S) transgenes with one mouse beta-globin allele. Blood Cells Mol Dis. 2001;27(6):971-977.

24. Kohli DR, Li Y, Khasabov SG, et al. Pain-related behaviors and neurochemical alterations in mice expressing sickle hemoglobin: modulation by cannabinoids. Blood. 2010;116(3):456-465.

25. Nath KA, Grande JP, Haggard JJ, Croatt AJ, Katusic ZS, Solovey A, Hebbel RP. Oxidative stress and induction of heme oxygenase- 1 in the kidney in sickle cell disease. Am J Pathol. 2001;158(3):893-903.

26. Liang DY, Clark JD. Modulation of the NO/CO-cGMP signaling cascade during chronic morphine exposure in mice. Neurosci Lett. 2004;365(1):73-77.

27. Quirion R, Finkel MS, Mendelsohn FA, Zamir N. Localization of opiate binding sites in kidney and adrenal gland of the rat. Life Sci. 1983;33(Suppl 1):299-302.

28. Neidle A, Manigault I, Wajda IJ. Distribution of opiate-like substances in rat tissues. Neurochem Res. 1979;4(3):399-410.

29. Hostetter TH. Hyperfiltration and glomerulosclerosis. Semin Nephrol. 2003;23(2):194-199.

30. Smeets B, Te Loeke NA, Dijkman HB, et al. The parietal epithelial cell: a key player in the pathogenesis of focal segmental glomerulosclerosis in Thy-1.1 transgenic mice. J Am Soc Nephrol. 2004;15(4):928-939.

31. Shankland SJ. The podocyte's response to injury: role in proteinuria and glomerulosclerosis. Kidney Int. 2006;69(12):2131-2147.

32. Ichikawa I, Ma J, Motojima M, Matsusaka T. Podocyte damage damages podocytes: autonomous vicious cycle that drives local spread of glomerular sclerosis. Curr Opin Nephrol Hypertens. 2005;14(3):205-210.

33. Johnson JE Jr, White JJ Jr, Walovitch RC, London ED. Effects of morphine on rat kidney glomerular podocytes: a scanning electron microscopic study. Drug Alcohol Depend. 1987;19(3):249-257. 
34. Senturk M, Irfan Kufrevioglu O, Ciftci M. Effects of some analgesic anaesthetic drugs on human erythrocyte glutathione reductase: an in vitro study. J Enzyme Inhib Med Chem. 2009;24(2):420-424.

35. Nath KA, Balla G, Vercellotti GM, et al. Induction of heme oxygenase is a rapid, protective response in rhabdomyolysis in the rat. J Clin Invest. 1992;90(1):267-270.

36. Patel J, Manjappa N, Bhat R, Mehrotra P, Bhaskaran M, Singhal PC. Role of oxidative stress and heme oxygenase activity in morphineinduced glomerular epithelial cell growth. Am J Physiol Renal Physiol. 2003;285(5):F861-F869.
37. Haymann JP, Stankovic K, Levy P, et al. Glomerular hyperfiltration in adult sickle cell anemia: a frequent hemolysis associated feature. Clin J Am Soc Nephrol. 2010;5(5):756-761.

38. Harris RC Jr. Cyclooxygenase- 2 inhibition and renal physiology. Am J Cardiol. 2002;89(6A):10D-17D.

\section{Publish your work in this journal}

The International Journal of Nephrology and Renovascular Disease is an international, peer-reviewed open-access journal focusing on the pathophysiology of the kidney and vascular supply. Epidemiology, screening, diagnosis, and treatment interventions are covered as well as basic science, biochemical and immunological studies. The journal welcomes original research, clinical studies, reviews \& evaluations, expert opinion and commentary, case reports and extended reports. The manuscript management system is completely online and includes a very quick and fair peerreview system, which is all easy to use. Visit http://www.dovepress.com/ testimonials.php to read real quotes from published authors.

Submit your manuscript here: http://www.dovepress.com/international-journal-of-nephrology-and-renovascular-disease-journal 